\title{
Surface Response to Mechanics of Hardness and Wear Characteristics of Nanoscale Hydrophobic Film
}

\author{
Akinsanya D. Baruwa ${ }^{{ }^{*},}$ Mamookho E. Makhatha ${ }^{1}$ and Esther T. Akinlabi ${ }^{2,3}$ \\ ${ }^{1}$ Department of Metallurgy, University of Johannesburg, South Africa \\ ${ }^{2}$ Directorate, Pan African University for Life and Earth Sciences, Ibadan, Nigeria \\ ${ }^{3}$ Department of Mechanical Engineering Science, University of Johannesburg, South Africa
}

\begin{abstract}
There is an increase in demand for durable and efficient organic nanoscale coatings for modern manufacturing systems or components for various applications. Due to this call, a new superhydrophobic silane compound was developed and deposited on mild steel, stainless steel and titanium substrates to determine its durability. The substrates are pretreated with alumina, and the coatings are deposited via the atomic layer deposition (ALD) method. The three substrates were considered for evolving properties comparison and determination of the substrates' response to the film's mechanical properties. The mechanical properties and the failure mechanics were investigated using nanoindentation and nanoscratch. The mechanical viability indicated that stainless steel showed the most robust properties compared with other substrates. Therefore, a nanoscale coating's mechanical strength can be influenced by the substrate's material compositions.
\end{abstract}

\subsection{Introduction}

The impact of chromium-based coatings on human health led to the clamour for alternative coating for surfaces of materials. Many coating materials were developed to eliminate the carcinogenic effect that most chromium-based exert on human health. Among the developed materials, using organic coating as a replacement was widely accepted by many researchers [1]. Afterwards, there are aggressive creations of diverse organic coatings for various applications such as aesthetic and protection [2], insulating and biomedical [3], microelectronics [4], among others. It found extensive use in the area of as anti-icing [5], medical [6], adhesion [7], semiconductors [8], and corrosion[9-11], to mention a view.

For a coating to function efficiently on a surface, the mechanical viability and mechanics have to be understood about substrate conformity and the coating process. The mechanical properties of a film are usually characterized by its deposition process, curing condition and chemical constituents [12]. The characteristics are determined through many methods; among them are the nanoindentation and scratch test due to their usefulness in measuring and understanding removal mechanism- scratch morphology-deformation relationship [13]. This relationship indicates that responses from nanoindentation and scratch tests can be transposed to wear properties.

\footnotetext{
*Corresponding author: darebaruwa@gmail.com
} 
Zheng et al. [14] investigated the failure mode mechanism of TiSiCON and TiSiCN films deposited on cemented carbide tools and observed that both cohesive and adhesive failures were found at the beginning and end of the scratch. It was also established from the investigation that the composite that contains oxygen has a better adhesion when compared with TiSiCN coating. TiFeN, TiN and TiFeMoN films were deposited on silicon wafer in application areas where massive shearing force and strain exposures are required [15]. It was discovered that films with $H / E_{r}>0.11$ exhibit delamination failure beyond scratch track while films with $H / E_{r} \leq 0.11$ exhibit combine hardness and toughness. Bartolomé et al. [16], also, deposited zinc dialkyldithiophosphate (ZDDP) tribofilms on diamond-like carbon (DLC) coatings and discovered that ZDDP tribofilm exhibited two mechanical responses. One response showed a linear elastic-plastic behaviour, while the other showed a compressed non-linear elastic behaviour.

A lot has been achieved concerning the mechanical behaviour of thin films. However, a stable mechanical strength has not been achieved with most of the organic thin films. Organic thin films found most of their applications in surface protection. The mechanical property usually found with the organic coating is rather adhesive strength than hardness or wear resistance. Nanoindentation and nanoscratch will be adopted for the investigation of newly developed organic compound (Repellix) to determine the behaviour of the films on different surfaces pretreated with alumina oxide

\subsection{Experimental}

\subsection{Materials and deposition process}

Superhydrophobic Repellix organic compound developed and prepared by Integrated Surface Technologies was used. Three substrates were considered for the experiment: AISI 304 stainless steel, mild steel, and Titanium grade 5. An atomic layer deposition (ALD) machine- RPX- 540 manufactured by IST was used for the deposition. The details of the deposition process and operating conditions have been provided elsewhere [17]. Before deposition of superhydrophobic Repellix, the surfaces of the substrates were first pretreated with alumina in the following steps via oxidation reactions:

$$
\begin{aligned}
& 2 \mathrm{AlOH}+2 \mathrm{Al}\left(\mathrm{CH}_{3}\right)_{3} \rightarrow 2\left[\mathrm{Al}-\mathrm{O}-\mathrm{Al}\left(\mathrm{CH}_{3}\right)_{2}+2 \mathrm{CH}_{4}\right. \\
& 2\left[\mathrm{Al}-\mathrm{O}-\left(3 \mathrm{H}_{3} \mathrm{O}\right)_{2} \rightarrow \mathrm{Al}_{2} \mathrm{O}_{3}+2 \mathrm{AlOH}+4 \mathrm{CH}_{4}\right.
\end{aligned}
$$

\subsection{Characterization}

Mechanical stability was investigated through a Hystron TI 950 TriboIndenter (Hystron, Minneapolis, MN, USA) with Triboscan v.9 software for data acquisition of nanoindentations. A depth-controlled method was used to determine the actual hardness and Young Modulus of the films using a Berkovich diamond tip indent of radius $50 \mathrm{~nm}$. A total of 15 indentations were made on every sample.

The nanoscratch was done using the Aton Paar micro/nano tester (USA) equipped with scratch 7.3.10 software and uses a Rockwell head with a radius of $100 \mu \mathrm{m}$. The scan was made at a progressive load from $3 \mathrm{mN}$ to $1000 \mathrm{mN}$ at a $50 \mathrm{~Hz}$ scan rate, $2 \mathrm{~mm} / \mathrm{min}$ of speed and scratch length of $1 \mathrm{~mm}$. 


\subsection{Results and Discussion}

\subsection{Nanoindentation}

The mechanical strength or stability of the films on different substrates is dependent on the difference in the morphological evolutions of the film on each substrate. The mean indentation data obtained are presented in Figure 1 and the calculated values in Table 1. In order to characterize the properties of a thin solid, nanoindentation has proved to be of great advantage for mechanical properties [18]. Therefore, nanoindentation is used to determine the hardness and Young Modulus of the films through the depth-controlled method. The characteristics are measured through Oliver-Pharr method [19] by describing the unloading data from an empirical power-law in Equation 3.

$$
P=\alpha\left(h-h_{f}\right)^{m}
$$

where $\alpha$ and $\mathrm{m}$ are empirical data determined by the fitting parameters and $h_{f}$ is the final displacement after complete unloading, and from curve fitting. $m=1.5$ for Berkovich indenter.

The hardness and Young's modulus are determined from Equations 4 and 5,

$$
\begin{aligned}
& H=\frac{P_{\max }}{A} \\
& \text { and } \\
& S=\left(\frac{d P}{d h}\right)_{h=h_{\max }}=\gamma\left(\frac{2}{\sqrt{\pi}}\right) E_{r} \sqrt{A}
\end{aligned}
$$

where A equals the projected contact area; $\mathrm{S}$ is the unloading stiffness, $h_{\max }$ is the maximum penetration depth, $\gamma$ depicts the correction factor due to the lack of axial symmetry and $E_{r}$ is the reduced modulus as prescribed in Equation 6.

$E_{r}$ can be expressed as

$$
\frac{1}{E_{r}}=\frac{1+v^{2}}{E}+\frac{1-v_{I}^{2}}{E_{I}}
$$

Where $E$ and $v$ are Young's modulus and the Poisson's ratio of the test material, however, $E_{I}$ and $v_{I}$ are Young's modulus and the Poisson's ratio of the indenter, respectively. The area, however, can be calculated from Equation 7,

$$
A=24.5 h_{c}^{2}
$$

where

$$
h_{c}=h_{\max }-\varepsilon \frac{P_{\max }}{S}
$$

The relationship between the stiffness and the $h_{c}$ is presented as Equation 9

$$
S=\frac{2}{\sqrt{\pi}} E_{r} \sqrt{24.5}\left(h_{c}+h_{d}\right)
$$


Where $h_{d}$ is the effective truncation length of the indenter tip- accommodated for the indenter-tip-rounding to determine the actual contact area.

Table 1 . The summary of the data calculated from the averaged indentations

\begin{tabular}{lllll}
\hline Sample & $\begin{array}{l}\text { Young Modulus } \\
\mathrm{E}(\mathrm{GPa})\end{array}$ & $\begin{array}{l}\text { Hardness } \\
\mathrm{H}(\mathrm{GPa})\end{array}$ & $\begin{array}{l}\text { Wear Resistance } \\
\mathrm{H}^{3} / \mathrm{E}^{2}(\mathrm{MPa})\end{array}$ & $\begin{array}{l}\text { Plasticity index } \\
\mathrm{H} / \mathrm{Er}\end{array}$ \\
\hline Stainless Steel & $52.85 \pm 2.05$ & $1.24 \pm 0.19$ & $682.61 \pm 058.11$ & $0.0235 \pm 0.0019$ \\
Mild Steel & $17.90 \pm 1.71$ & $0.25 \pm 0.08$ & $487.66 \pm 025.07$ & $0.0140 \pm 0.0031$ \\
Titanium & $06.84 \pm 1.08$ & $0.10 \pm 0.02$ & $213.74 \pm 019.29$ & $0.0146 \pm 0.0014$ \\
\hline
\end{tabular}

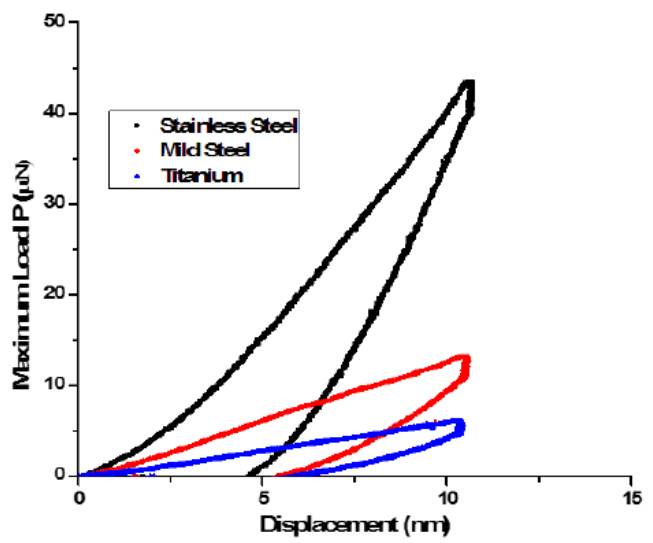

Figure 1: Depicts the load-displacement curve of stainless steel, mild steel and Titanium

From Figure 1, it could be seen that substrates have an essential role in the behavioural modalities of a deposited film. Difficult depth-dependent hardness values are observed on the coatings on different substrates. It takes the indenter to reach a maximum of $44 \mu \mathrm{N}$ load to penetrate the film deposited on the stainless steel, while mild steel and Titanium required just $10 \mu \mathrm{N}$ and $5 \mu \mathrm{N}$ respectively. The low load requirement of Titanium could also be attributed to pores found in the microstructure of the Titanium (not shown). This means that the film deposited on stainless steel has better hardness than mild steel, and mild steel performs better than Titanium. Equations 3 to 9 were used to calculate the hardness, Young's modulus, wear-resistance and plasticity index. The summary of the characterization and calculations are presented in Table 1. The averaged indentations carried out in this experiment shows that coating deposited on the stainless steel has the highest Young's modulus and hardens of $1.24 \mathrm{GPa}$ and $52.5 \mathrm{GPa}$ with a standard deviation of $0.94 \mathrm{GPa}$ and 45.67 GPa, respectively. These values are higher than Repellix films on both mild steel and Titanium. The low hardness and Young's modulus noticed in titanium substrate could be as a result of the vast pores observed in its structure (not shown). The least hardness and Young's modulus are found in the film deposited on the mild steel (MS) with values at 0.10 $\mathrm{GPa}$ and $0.68 \mathrm{GPa}$ with a standard deviation of $0.10 \mathrm{GPa}$ and $6.84 \mathrm{GPa}$. More so, the film's resistance to plastic deformation (wear) and plasticity index (the utmost) was also determined through nanoindentation [20]. Although the coating on mild steel has the lowest plastic index- a sign of good wear resistance, the high $\mathrm{H}^{3} / \mathrm{E}^{2}$ ratio, however, defeated its wear resistance. Stainless steel has both high plasticity index $\mathrm{H} / \mathrm{E}$ and wear resistance $\left(\mathrm{H}^{3} / \mathrm{E}^{2}\right)$ ratio. It was established that High $\mathrm{H} / \mathrm{E}$ and $\mathrm{H}^{3} / \mathrm{E}^{2}$ ratios could also be beneficial in the rate of wear 
reduction [21]. The disparity in the set of data derived could be a result of the chemical compositions altered during preheating of the substrates. It could also be responsible for the difference in the microstructural evolution of the substrates due to heat. This analogy is in agreement with the work of Nunes and Piedade [22]. It is worthy of establishing that the high standard deviation observed from the data results from the hierarchical structures of the superhydrophobic coatings.

\subsection{Nanoscratch}

The mechanical strength of the Repellix deposit was also characterized through nanoscratch. Nanoscratch is a useful method for investigating the nature of wear, fracture, and friction in material remover mechanisms [23]. The coefficient of friction and the penetration details acquired from the tests are presented in Figure 2. The resultant coefficient of friction of the composite deposited on stainless steel is 0.033 , mild steel 0.029 and 0.032 on Titanium. These values are very close, and it is an indication that the film adheres strictly to the substrates irrespective of surface response to the formation of the structure. It also means that the hardness and Young's modulus on each substrate could differ, but it is not a factor determining the compound's adherence to the substrates.
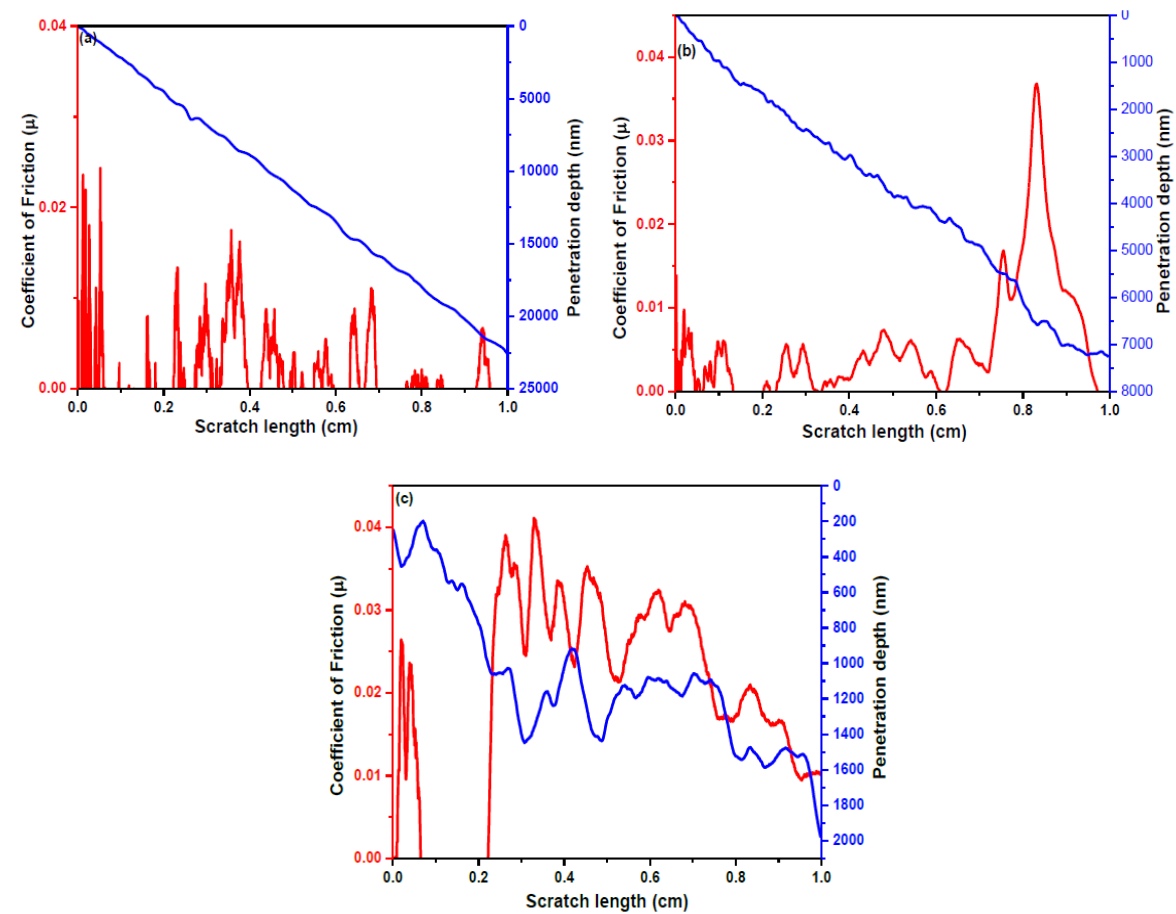

Figure 2: Penetration depth and coefficient of friction of the Repellix-alumina composite on a) Stainless steel (SS), b) Mild steel (MS), and c) Titanium (Ti)

From Figure 2, the effect of roughness is observed on the pattern of the coefficient of friction. Zero coefficients of friction are detected in stainless steel and titanium coated surfaces. This phenomenon is associated with air traps (gaps between particles) as a result of hierarchical structures in the films. The penetration depth, however, shows a different pattern. The scratch depth of stainless steel plunges smoothly while mild steel and Titanium plunge roughly into 
the composite. The rough plunges could result from roughness or wear chipping due to plasticity along the scratch track.
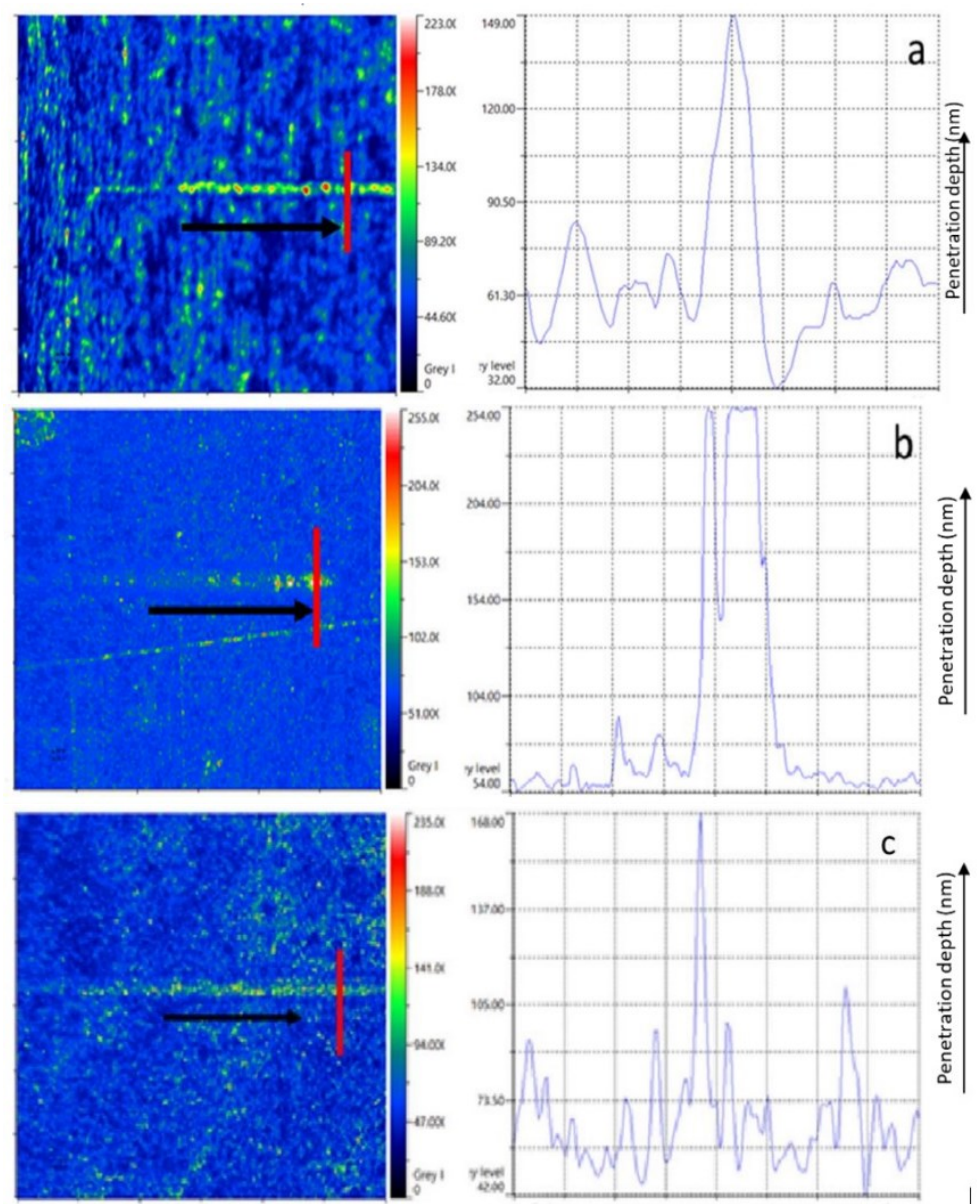

Figure 3: Penetration depth of measurement towards the end of the scratch of a) stainless steel, b) mild steel, and C) Titanium

Figure 3 shows the measurement of wear depth toward the end-tip of the scratch. Indenter encroached deeper into the composite of mild steel up to $254 \mathrm{~nm}$, while stainless steel and titanium composites have $148 \mathrm{~nm}$ and $168 \mathrm{~nm}$, respectively. High penetration could result from the smoothness of the surface, or the indenter had a smoother scratch without big particles obstructing the process. Consequently, Feng et al. [24] attributed the depth of penetration to the degree of crosslinked agent present in a compound's chemical matrix. The lower penetration depth observed in the films deposited on stainless steel and Titanium surfaces describes their toughness and resistance ability [25]. However, the coating on the surface of stainless steel does not show good adhesion.

\subsection{Conclusion}

A newly developed organic compound deposited on the surfaces of selected metals pretreated with alumina was characterized for mechanical properties. Mechanical tests proved that the 
coating deposited on stainless steel outperformed other substrates at both investigating methods. It also affirms that hardness cannot be the sole determinant factor in ascertaining the mechanical integrity of a coating or surface. Therefore, it can be said that the film deposited on the stainless steel could be durable more than the films deposited on mild steel and Titanium. In conclusion, an organic compound could be used for coating surfaces that require good mechanical properties when it forms a composite with inorganic structures as a surface pretreatment.

\section{Acknowledgement}

The authors would like to thank the management of the University of Johannesburg for the financial support for this project.

\section{References}

1. R. Figueira, I. Fontinha, C. Silva, and E. Pereira, Coatings 6, 12 (2016)

2. F. Deflorian, S. Rossi, and L. Fedrizzi, Electrochim. Acta 51, 6097 (2006)

3. K. Pacaphol and D. Aht-Ong, Surf. Coatings Technol. 320, 70 (2017)

4. H. Kim, J. Vac. Sci. Technol. B Microelectron. Nanom. Struct. 21, 2231 (2003)

5. P. Nguyen-Tri, H. N. Tran, C. O. Plamondon, L. Tuduri, D. V. N. Vo, S. Nanda, A. Mishra, H. P. Chao, and A. K. Bajpai, Prog. Org. Coatings 132, 235 (2019)

6. G. Mani, M. D. Feldman, S. Oh, and C. M. Agrawal, Appl. Surf. Sci. 255, 5961 (2009)

7. J. Liang, X. W. Wu, Y. Ling, S. Yu, and Z. Zhang, Surf. Coatings Technol. 339, 65 (2018)

8. D. A. Tropin and A. V. Fedorov, J. Loss Prev. Process Ind. 49, 762 (2017)

9. X. Cui, G. Zhu, Y. Pan, Q. Shao, C. (xinxin) Zhao, M. Dong, Y. Zhang, and Z. Guo, Polymer (Guildf). 138, 203 (2018)

10. M. L. Zheludkevich, R. Serra, M. F. Montemor, K. A. Yasakau, I. M. M. Salvado, and M. G. S. Ferreira, Electrochim. Acta 51, 208 (2005)

11. M. M. Khalaf and H. M. Abd El-Lateef, Mater. Chem. Phys. 177, 250 (2016)

12. J. Gao, H. Lv, X. Zhang, and H. Zhao, Prog. Org. Coatings 76, 1477 (2013)

13. P. Kardar, M. Ebrahimi, and S. Bastani, Prog. Org. Coatings 62, 321 (2008)

14. Y. J. Zheng, Y. X. Leng, X. Xin, Z. Y. Xu, F. Q. Jiang, R. Wei, and N. Huang, Vacuum 90, 50 (2013)

15. B. D. Beake, V. M. Vishnyakov, and A. J. Harris, Tribol. Int. 44, 468 (2011)

16. L. Bartolomé, E. Oblak, and M. Kalin, Tribol. Int. 95, 19 (2016)

17. E. T. Akinlabi, A. D. Baruwa, O. P. Oladijo, N. Maledi, and J. Chinn, J. Mater. Eng. Perform. 1 (2019)

18. G. A. Crawford, N. Chawla, M. Koopman, K. Carlisle, and K. K. Chawla, Adv. Eng. Mater. 11, 45 (2009)

19. W. C. Oliver and G. M. Pharr, J. Mater. Res. 19, 3 (2004)

20. A. Leyland and A. Matthews, Wear 246, 1 (2000)

21. S. Hassani, M. Bielawski, W. Beres, L. Martinu, M. Balazinski, and J. E. Klemberg-Sapieha, Surf. Coatings Technol. 203, 204 (2008)

22. J. Nunes and A. P. Piedade, Appl. Surf. Sci. 284, 792 (2013)

23. H. Zhou, S. Qiu, X. Zhang, and C. Xu, Appl. Surf. Sci. 258, 9756 (2012)

24. L. Feng, B. (Nadia) Benhamida, C. Y. Lu, L. P. Sung, P. Morel, A. T. Detwiler, J. M. Skelly, L. T. Baker, and D. Bhattacharya, Prog. Org. Coatings 125, 339 (2018)

25. H. Li, J. Li, Z. Liu, J. Huang, J. Kong, and D. Xiong, Surf. Coatings Technol. 375, 589 (2019) 